\title{
Awareness and Attitude of Maritime Students Towards the Introduction of Autonomous Merchant Ships - Preliminary Results
}

\author{
J. Nasur \& K. Bogusławski \\ Gdynia Maritime University, Gdynia, Poland
}

\begin{abstract}
Autonomous merchant shipping has become a topic of discussions and studies as the available technology enables it to become a possible alternative to conventional ships manned with seafarers. The present study reviews the results of a survey conducted worldwide amongst the students of maritime universities. The students were asked about their understanding of autonomous merchant ships and an attitude towards them. The study finds that the vast majority of interviewees claims to have an average or below average knowledge of the topic, and perceive automation as a factor increasing safety at sea, while threatening seafaring jobs. The results suggest that the topic of autonomous shipping should be more touched upon in curriculums of maritime universities, as the students appear to have a limited understanding of what can potentially become a future of their prospective occupation.
\end{abstract}

\section{INTRODUCTION}

The idea of developing an autonomous merchant ship (carrying passengers or goods by the sea with a limited human intervention) has been pursued by shipping companies and other industry actors for the past few years. As of April 2020, there are some prototypes being tested, or in preparation (Felski \& Zwolak, 2020). However, it remains unknown how, or when such ships will become fully operational (Kooij et al., 2018) and whether their operations will be feasible (Wróbel et al., 2017). Nonetheless, it can be safely assumed that they will at some point be introduced to the maritime industry, and will eventually become a significant mode of transporting goods and passengers (Bitar, 2017).

The sustainability of such vessels comes with the need of redefining the role of seafarers and other maritime personnel (Cicek et al., 2019; Lokuketagoda et al., 2018). The issue of preparing the maritime workforce for the upcoming shift is already being discussed by numerous authors (Emad et al., 2020; Fan et al., 2020; Lutzhoft et al., 2019; Sharma et al., 2019). However, to our best knowledge, cadets' attitudes or points of view have not been investigated to date. Meanwhile, future seafarers are continuously being educated and trained in many Maritime Education and Training (MET) institutions around the world. Moreover, introducing autonomous ships and technological progress in the marine industry are indicated as some of the reasons for the continuous improvement of seafarers' skills (Yuen et al., 2018). Thus, in order to secure the sustainability of the maritime training process, cadets' perspectives must be scrutinized and addressed.

Some research concerning the mariners' attitude towards Maritime Autonomous Surface Ships (MASS), has been conducted in recent years (Nautilus Federation, 2018; World Maritime University, 2019). However, those studies were focused on the opinion 
of experienced seafarers. It is also important to investigate what attitude do the students of maritimerelated topics have. They intend to advance their maritime careers and will inevitably be affected by any disruptive changes to it. Therefore, the aim of this study is to bridge this gap and identify the awareness and attitude of maritime students towards introducing the autonomous merchant ships. The findings of this study can be found relevant and interesting by scholars and lecturers at METs, regarding the topic coverage in curricula. Additionally, maritime administration, as well as seafarers' unions and other public institutions may be interested in seeing the perceived job insecurity caused by automation.

The paper is organized as follows. In Section 2, methods utilized in the study are presented and described. Section 3 introduces results of the survey along with their analysis. In Section 4, the main findings are discussed, while Section 5 concludes the paper.

\section{METHODS}

In the study, conducted at the turn of February and March 2020, we asked students of maritime-related studies to answer a total of 18 questions, in order to check their views concerning MASS. The form was sent to the teachers and officials of maritime universities along with a request to share it amongst their students.

The survey was conducted through an online survey platform. Before starting the survey, the questionnaire was sent to three maritime students in order to validate the survey form. Since we received positive feedback, no further changes were made to the questionnaire. The answers of the testers are thus included in the results.

In total, we received 338 individual responses. Among these, we rejected eight, because they did not meet the requirements of participation.

The questions 1-6 concerned the demographic background of the respondents. The question 7 concerned their opinion about their overall familiarity with the topic of MASS. The survey would terminate upon responding: The topic is unknown to me. Consequently, the questions 8-18 concerned respondents' attitude and awareness of the topic, as well as its exploration during maritime studies.

\section{RESULTS}

\subsection{Demographic data}

Out of 330 respondents, $73.6 \%$ were males, $25.2 \%$ were females, remaining $1.2 \%$ were non-binary or preferred not to state their gender. A vast majority $(91.2 \%)$ was less than twenty-two years old.

Table 1 depicts demographic breakdown of the surveyed students by the countries of origin, affiliated universities and majors of studies.
The highest number of respondents affiliated with Maritime Academy of Asia and the Pacific (MAAP) in Philippines (39.7\%), however, when combining the answers, the majority of respondents $(60.3 \%)$ studied in European METs. Most of the respondents (83.3\%) have been studying maritime-oriented majors for no more than three years.

Table 1. Demographic breakdown of the respondents

\begin{tabular}{lc}
\hline Country of origin & Number of respondents \\
\hline Philippines & 131 \\
Russia & 77 \\
Poland & 54 \\
Belgium & 24 \\
Romania & 18 \\
France & 6 \\
Other & 19
\end{tabular}

\begin{tabular}{lc}
\hline Affiliated university & Number of respondents \\
\hline Maritime Academy of Asia and the Pacific & 131 \\
Admiral Makarov State University of & 84 \\
$\quad$ Maritime and Inland Shipping & \\
Gdynia Maritime University & 46 \\
Antwerp Maritime Academy & 31 \\
Constanta Maritime University & 19 \\
Maritime University of Szczecin & 10 \\
World Maritime University & 7 \\
Estonian Maritime Academy & 1 \\
Studies major & Number of respondents \\
\hline Navigation & 161 \\
Transport and logistics & 90 \\
Marine engineering & 72 \\
Administration & 4 \\
Electrical engineering & 1 \\
IT & 1 \\
\hline
\end{tabular}

\subsection{Results of the survey}

When asked about their familiarity with the topic of MASS, $88 \%$ of the respondents rated their knowledge as no higher than average (Fig.1.). The respondents were then asked how they feel about increasing ship automation (Fig.2.) and where did they know the term autonomous merchant ship from, in the form of a multiple choice question (Fig.3.). The most selected sources were: maritime-oriented websites (54\%), lectures (47\%) and discussions with other students $(39 \%)$. The vast majority of the students $(70 \%)$ rated the coverage of the MASS topic within their major curricula as average or below average (Fig.4.). 


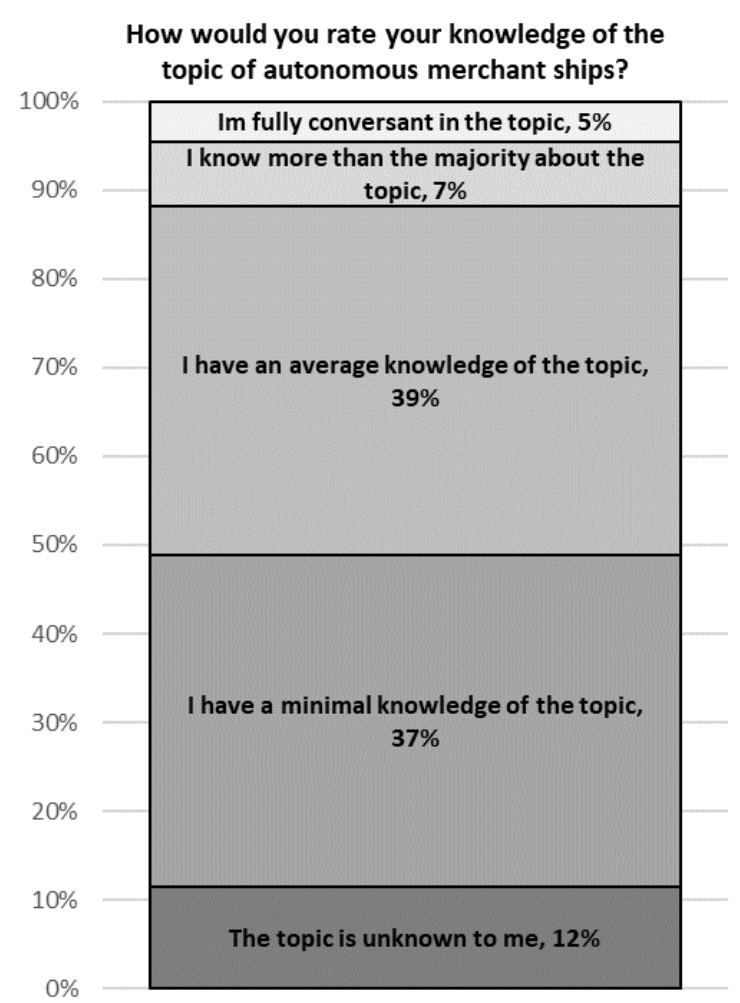

Figure 1 Respondents' knowledge about MASS

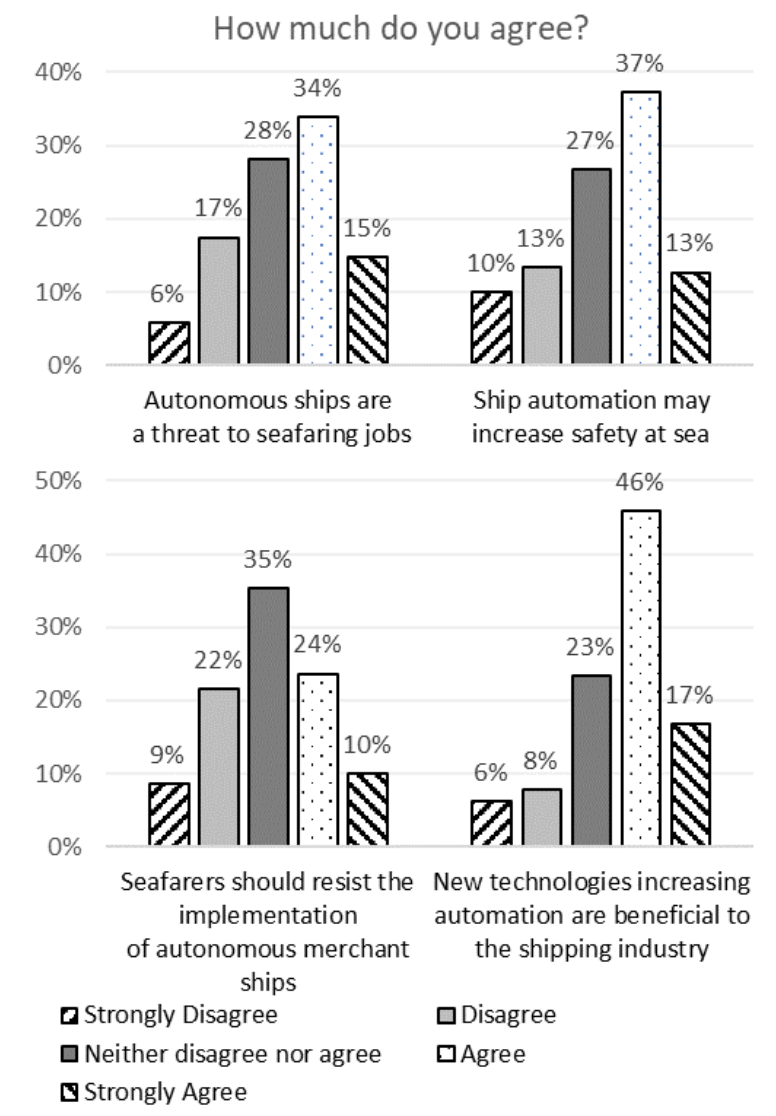

Figure 2. Cumulative results of the respondents' agreement with statements about MASS

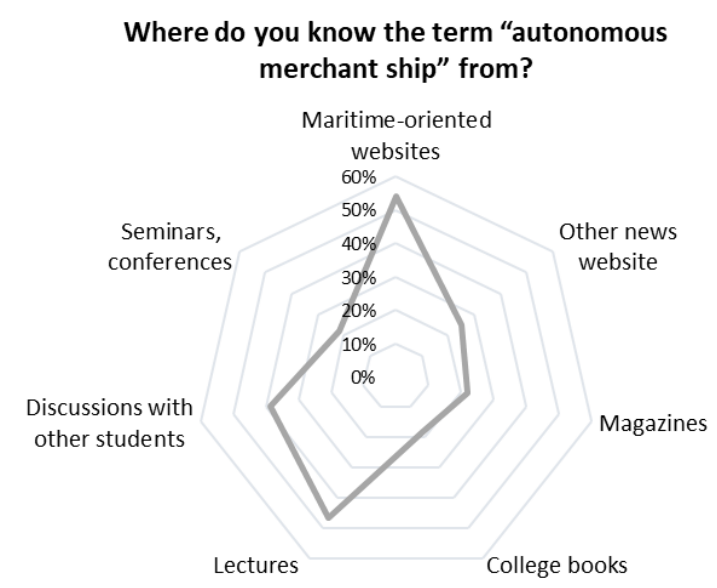

Figure 3. Sources of entrants' knowledge about MASS

How well is the topic of autonomous merchant ships touched upon in your studies' curriculum?

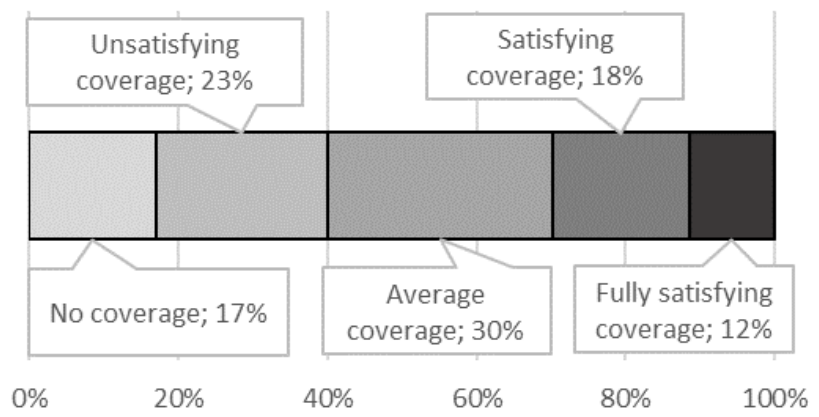

Figure 4. Coverage of the MASS topic in respondents' METs

As can be noticed from Figure 2:

- Nearly half of the respondents (49\%) agree that autonomous ships are a threat to seafaring jobs;

- Almost every fourth student (23\%) thinks that ship automation may not increase safety at sea;

- Roughly one in three respondents (35\%) neither disagrees nor agrees that seafarers should resist the implementation of MASS;

- $63 \%$ of the students perceive new technologies increasing automation as beneficial to the shipping industry.

\section{DISCUSSION}

The analysis of collected data reveals that the knowledge of the MASS topic amongst maritime students is average, at most (see Fig.1). Meanwhile, more than half of the students predict that autonomous ships will relatively soon become a majority in merchant shipping, which means that they expect them to appear during their seafaring career span. Such prognosis suggests that students should achieve a better understanding of prospective changes to their occupational domain. While the coverage of the topic at the respondents' METs varies, only one in ten students is fully satisfied with its scope (Fig.4). Reportedly, the most common sources 
of information pertaining to MASS were maritimeoriented websites (Fig.3). This may suggest that the topic is rarely touched upon in general news, as well as in curricula. Finally, it indicates that students continue to be interested in issues related to their future occupation and seek additional information outside the classrooms. On the other hand, the very purpose of professional training is to get familiar with the intended working domain, while gaining necessary skills.

Autonomous ships are considered to be a threat to seafaring jobs by only a half of the respondents, which is far less than amongst professionals ((Nautilus Federation, 2018). Not knowing the respondents' actual rationale behind such statements, we may only speculate that these may be the following:

- a generally positive attitude of the $\mathrm{Z}$ generation towards technology (Turner, 2015) - where entrants see technologies as tools to achieve their goals rather than phenomena that can make their workplaces obsolete;

- a belief that seafaring jobs are in fact uneasy to fully automate due to its complexity and cognitive workload required particularly on operational and management levels (Frey \& Osborne, 2017) - a view that is partially supported by ;

- a potential lack of a developed occupational ethos and commitment to the work position.

Interestingly, students perceive ship automation as a potential way of increasing safety at sea, while the majority of experienced seafarers state it may pose a threat to safety (Nautilus Federation, 2018). Such difference in entrants' and professional seafarers' attitudes may be caused by the lack of seagoing experience of the former. Noteworthy, scientific data appears to be ambiguous in this respect (Wróbel et al., 2017).

An interesting speculation can be drawn from entrants' responses to the question whether seafarers should resist the implementation of autonomous merchant ships, either by themselves or through official unions and other public institutions. As presented in Figure 2, only every third respondent agreed with this statement (significantly less than those seeing automation as a threat to job positions $49 \%$ ). This may indicate that:

- entrants do not have faith in the ITF's (International Transport Workers' Federation) ability to defend seafarers' positions or

- entrants believe they will easily find work in other fields even if their original positions are replaced by automation.

It is also worth noting, that despite $63 \%$ of respondents stating that ship automation is beneficial to the shipping industry in general, only $49 \%$ see it as a threat to seafaring jobs. Such difference may be caused by some students thinking that the automatization will be limited to ships with automated processes and decision support, with seafarers present on board to operate and control shipboard systems and functions (Degree of Automation 1, as classified by International Maritime Organization (Chae et al., 2020; Wróbel et al., 2020)). Through this scheme, automation would aid seafarers in their daily tasks making their jobs easier but not threatening their existence. This might indicate a high level of self-confidence among prospective seafarers who think that their contribution to the global shipping industry is non-replaceable (Kim, 2017). Sadly or not, restricting the drive towards autonomy to only this aspect may prove impossible.

The uncertainties and limitations of the study can result from:

- relatively small sample size;

- limited geographical diversity of surveyed METs;

- potential misinterpretation of questions by respondents.

For an improved understanding of entrants' viewpoints on MASS, the following should be studied deeper: a perceived coverage of MASS topic in particular METs, the correlation between topic coverage in METs on respondents attitude towards MASS, respondents' prospects on working ashore, i.e. in Shore Control Centers.

What is also noteworthy, the study was carried out during the early stages of the global outbreak of SARS-CoV-2. The expected global economic recession (Ozili \& Arun, 2020) may cause a significant change of the perceived job security within the shipping industry. Its impact on the maritime job market as well as on the process of maritime autonomization are difficult to predict as of early April 2020.

\section{CONCLUSION}

The main objective of this research was to study the awareness and attitude of maritime students on autonomous merchant ships. The most important findings of the study are: the coverage of MASS topic in respondents' METs is mostly below a satisfying level, their knowledge is mainly average, at most. Statistically, the respondents perceive automation as beneficial to safety at sea, but not as a threat to seafaring jobs. By producing these conclusions, we have achieved the main goal of our study.

\section{ACKNOWLEDGEMENTS}

The authors, second year students of Navigation at GMU, are grateful to all students who participated in the study as well as their teachers who forwarded the survey form to them. The assistance of Krzysztof Wróbel and Mateusz Gil of Gdynia Maritime University was kindly appreciated. The authors would also like to thank Prof. Adam Weintrit for inspiration and helping in survey distribution.

\section{REFERENCES}

Bitar, G. I. (2017). Towards the Development of Autonomous Ferries. https://ntnuopen.ntnu.no/ntnuxmlui/handle/11250/2465617

Chae, C.-J., Kim, M., \& Kim, H.-J. (2020). A Study on Identification of Development Status of MASS Technologies and Directions of Improvement. Applied Sciences, 10(13), https://doi.org/10.3390/app10134564 
Cicek, K., Akyuz, E., \& Celik, M. (2019). Future Skills Requirements Analysis in Maritime Industry. Procedia Computer Science, 158, 270-274. https://doi.org/10.1016/j.procs.2019.09.051

Emad, G. R., Khabir, M., \& Shahbakhsh, M. (2020, January 1). Shipping 4.0 and Training Seafarers for the Future Autonomous and Unmanned Ships.

Fan, C., Wróbel, K., Montewka, J., Gil, M., Wan, C., \& Zhang, D. (2020). A framework to identify factors influencing navigational risk for Maritime Autonomous Surface Ships. Ocean Engineering, 202, 107188. https://doi.org/10.1016/j.oceaneng.2020.107188

Felski, A., \& Zwolak, K. (2020). The Ocean-Going Autonomous Ship-Challenges and Threats. Journal of Marine Science and Engineering, 8(1), 41. https://doi.org/10.3390/jmse8010041

Frey, C. B., \& Osborne, M. A. (2017). The future of employment: How susceptible are jobs to computerisation? Technological Forecasting and Social Change, 114, 254-280. https://doi.org/10.1016/j.techfore.2016.08.019

Kim, J. (2017). Job security awareness in relation to job continuity for seafarers sailing on international ships. World Maritime University Dissertations. https://commons.wmu.se/all_dissertations/564

Lokuketagoda, G., Miwa, T., Jayasinghe, S. G., \& Ranmuthugala, S. D. (2018). Training engineers for remotely operated ships of the future. 19th Annual General Assembly-AGA 2018, 207-214.

Lutzhoft, M., Hynnekleiv, A., Earthy, J. V., \& Petersen, E. S. (2019). Human-centred maritime autonomy-An ethnography of the future. Journal of Physics:
Conference

Series,

1357,

https://doi.org/10.1088/1742-6596/1357/1/012032

Nautilus Federation. Future proofed? What maritime professionals think about autonomous shipping. (n.d.).

Ozili, P., \& Arun, T. (2020). Spillover of COVID-19: Impact on the Global Economy. SSRN Electronic Journal. https://doi.org/10.2139/ssrn.3562570

Sharma, A., Kim, T., \& Nazir, S. (2019, October 18). Catching up with time? Examining the STCW competence framework for autonomous shipping.

Turner, A. (2015). Generation Z: Technology and Social Interest. The Journal of Individual Psychology, 71(2), 103-113. https://doi.org/10.1353/jip.2015.0021

World Maritime University. (2019). Transport 2040: Autonomous ships: A new paradigm for Norwegian shipping - Technology and transformation. Reports. http://dx.doi.org/10.21677/itf.20190715

Wróbel, K., Gil, M., \& Montewka, J. (2020). Identifying research directions of a remotely-controlled merchant ship by revisiting her system-theoretic safety control structure. Safety Science, 129, 104797. https://doi.org/10.1016/j.ssci.2020.104797

Wróbel, K., Montewka, J., \& Kujala, P. (2017). Towards the assessment of potential impact of unmanned vessels on maritime transportation safety. Reliability Engineering \& System Safety, 165, 155-169. https://doi.org/10.1016/j.ress.2017.03.029

Yuen, K. F., Loh, H. S., Zhou, Q., \& Wong, Y. D. (2018). Determinants of job satisfaction and performance of seafarers. Transportation Research Part A: Policy and Practice, 110 , https://doi.org/10.1016/j.tra.2018.02.006 